\title{
Analysis of Influence Factors of Tide-Dominated Estuaries Based on Deposition Numerical Simulation
}

\author{
Tao Tang ${ }^{1}$, Jixin Huang ${ }^{2}$, Yanshu Yin ${ }^{1 *}$, Wenjie Feng ${ }^{1}$ \\ ${ }^{1}$ School of Geosciences, Yangtze University, Wuhan, China \\ ${ }^{2}$ America Branch, Research Institute of Petroleum Exploration \& Development, Beijing, China \\ Email: *15649178238@163.com
}

How to cite this paper: Tang, T., Huang, J.X., Yin, Y.S. and Feng, W.J. (2018) Analysis of Influence Factors of TideDominated Estuaries Based on Deposition Numerical Simulation. Open Journal of Yangtze Gas and Oil, 3, 139-146. https://doi.org/10.4236/ojogas.2018.32012

Received: December 26, 2017

Accepted: April 25, 2018

Published: April 28, 2018

Copyright $\odot 2018$ by authors and Scientific Research Publishing Inc. This work is licensed under the Creative Commons Attribution International License (CC BY 4.0).

http://creativecommons.org/licenses/by/4.0/

\begin{abstract}
Tide-dominated estuaries sedimentary reservoir is a hot area of sedimentology research in recent years, and the important target of oil and gas exploration is one of the relatively few sedimentary systems. Based on the study of underground reservoirs, outcrop and modern sedimentation, scholars believe that the estuary is a sedimentary system formed by transgressive system tract, which is composed of a complex subfacies environment with obvious changes. Its formation is influenced by many factors. The purpose of this paper is to simulate the deposition process of estuaries by Delft-3D software, and to reveal the main controlling factors of estuarine reservoir formation. The factors are as follows. 1) The size of the river flow has a destructive effect on the formation of the estuarine sand bar in the estuary, but the effect is small. 2) Tidal energy plays a constructive role in estuarine sand bars in estuaries, and it is also the main force for the formation of estuarine reservoirs. 3) The composition of the sediments has an obvious influence on the formation of the estuarine reservoir, and the content of the mud is an important factor for the retention of the estuarine sand bar.
\end{abstract}

\section{Keywords}

Deposition Numerical Simulation, Tide-Dominated Estuary, Influence Factor, Oil Exploration

\section{Introduction}

An estuary is a transgressive coastal environment at the mouth of a river, which receives sediment from both fluvial and marine sources, and that contains facies 
influenced by tide, wave and fluvial processes. The estuary is considered to extend from the landward limit of tidal facies at its head to the seaward limit of coastal facies at its mouth [1]. Sandbody, differing from the delta system, is relatively fine in the middle and thick in the both ends. In the research and analysis of the formation mechanism of reservoir stratum in estuary, it is found that due to the influence of bimodal current and supply of multiple materials, the reservoir sand body in estuaries often presents the diversity and complexity, for example, the distribution of sand sheet, channel point bar and river mouth bar is complex. With deepening of the exploration and development of oil and gas in the estuary, it is a hotspot of sedimentology and reservoir geology to analyze main controlling factors for formation of reservoir in estuaries. However, since the outcrop of estuaries is less and the well drilling study on recognition of reservoir in estuaries is much less, the study on reservoir in estuary is confronted with great challenges.

In recent years, the University of Duran in the Netherlands has developed a sedimentation numerical simulation software Delft-3D for estuarine and coastal management. It can simulate the sediment transport and accumulation process in estuaries under the interaction of rivers and tides. The sedimentology research has always advocated the principle of the modern and the ancient [2]. Therefore, the application of sedimentation numerical simulation technology in sedimentology research has become a hot topic at present. This paper attempts to use Delft-3D software to simulate tidal-dominated estuary reservoir. It also reveals the formation process of different types of reservoir sand bodies, and summarizes the main controlling factors of sand body formation in different reservoirs. It lays a foundation for sand body prediction and oil and gas exploration of tidal control estuary reservoir.

\section{Boundary Conditions of Sedimentary Numerical Simulation}

To observe the forming process and controlling factors of estuary deposit, Delft-3D was used to simulate the development process of estuary and summarize its characteristics, and constructed sedimentary numerical simulation bed form by taking the typical modern Fitzroy estuary under the control of tides. The experimental design of sedimentation numerical simulation is as bellow (Figure 1):

The main sediment source has a full length of about $98 \mathrm{~km}$. The length of the river is about $60 \mathrm{~km}$ and about $32 \mathrm{~km}$ at the river mouth. The estuary is about $1.1 \mathrm{~km}$ in width; and the total simulated grid is $29 \times 650$. Simulation parameters are shown in Table 1, which were acquired through sedimentation physical simulation experiments and analysis of former numeric simulation tests, including flow, tidal range, sand-mud ratio, sand and mud dry weight, river discharge, and the topography parameters. Then in the paper, the main controlling factors for the formation of estuary were revealed through single factor analysis. 


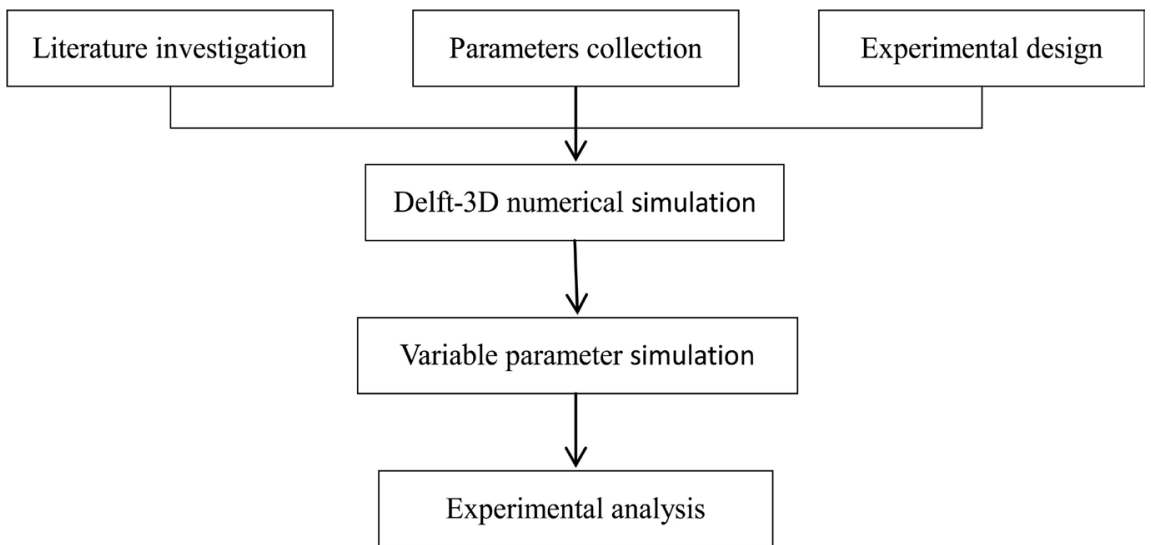

Figure 1. Technical roadmap of sedimentation numerical simulation.

Table 1. Boundary conditions of sedimentary numerical simulation.

\begin{tabular}{|c|c|c|c|c|c|c|c|c|c|c|c|}
\hline Parameter & $\begin{array}{c}\text { median } \\
\text { size/mm }\end{array}$ & $\begin{array}{c}\text { bottom } \\
\text { bed } \\
\text { slope/ }\left(^{\circ}\right)\end{array}$ & sand/mud & $\begin{array}{l}\text { sand dry } \\
\text { weight } \\
/\left(\mathrm{kg} \cdot \mathrm{m}^{-3}\right)\end{array}$ & $\begin{array}{l}\text { mud dry } \\
\text { weight } \\
/\left(\mathrm{kg} \cdot \mathrm{m}^{-3}\right)\end{array}$ & $\begin{array}{c}\text { river } \\
\text { discharge } \\
/\left(\mathrm{m}^{3} \cdot \mathrm{s}\right)\end{array}$ & $\begin{array}{c}\text { velocity of } \\
\text { flow/ } \\
(\mathrm{m} \cdot \mathrm{s})\end{array}$ & $\begin{array}{c}\text { tidal } \\
\text { range/m }\end{array}$ & $\begin{array}{l}\text { geomorphic } \\
\text { factor/1 }\end{array}$ & $\begin{array}{c}\text { acceleration } \\
\text { of gravity } \\
/\left(\mathrm{m} \cdot \mathrm{s}^{-2}\right)\end{array}$ & $\begin{array}{l}\text { Mesh } \\
\text { count }\end{array}$ \\
\hline Value Set & 0.2 & 0.005 & 1:05 & 500 & 2500 & 1000 & $0.8-2.2$ & 4 & 100 & 9.81 & $29 \times 650$ \\
\hline
\end{tabular}

\section{Forming Process of Tide-Dominated Estuary and Causes of Formation of Sandbars}

The estuary sedimentation is under bilateral control of rivers and tides, thus the sedimentation process is more complex. As is shown in Figure 2, when the simulated step length is lower than 1000 , it can be seen that the river will carry sand in the bed to the river mouth, and meanwhile, sand in the bed of the river mouth will gradually pile up under the influence of tides. There are point bars within the river way but sand bars cannot be seen at the river mouth. In the process of this stage, fresh water brought by rivers will quickly blend with sea water, and sea water with a high salinity will invade the river mouth from the bottom, thus making water in upper and lower levels flow in the opposite directions [3]. With the increasing of simulated step length and continuous alteration of ebbs and floods tide, there will be changing bimodal currents within the river way and the river mouth to segment sand and form river mouth bars. River mouth bars can be easily found when the simulated step length reaches to 1500. When sediments keep on increasing, the center of river mouth sand bar will continue to grow and the thickness will gradually increase. Moreover, the tide way will become more complex. Meanwhile, big currents will erode sandbar edges, thus form sand sheets around the sandbar edges [4]. In later stages of the sedimentation process, parts of tide gates will start to be abandoned and filled in by sediment and most sand bars will start to connect and form an integral whole. The simulation revealed the forming process of sand within tide-dominated estuary due to different causes, which could correspond to the practically observed formation and distribution of sand within modern tide-dominated estuary. Thus, it 
indicated that the sedimentary numerical simulation could reveal causes for the formation of tide-dominated estuaries. Therefore, it is possible to reveal main controlling factors for the formation of tide-dominated estuaries through single factor tests.
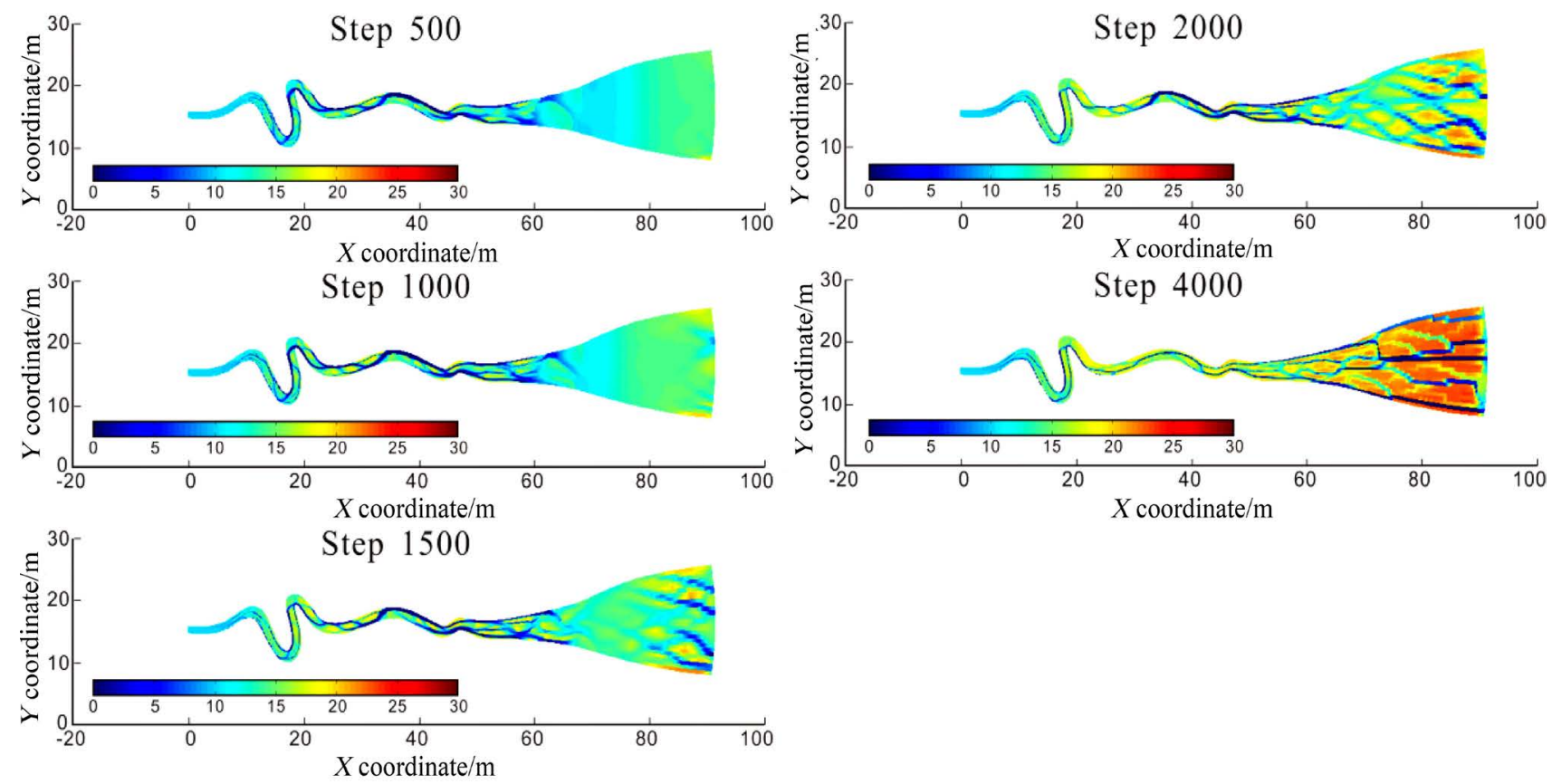

Figure 2. Numerical simulation and deposition process of estuary.

\section{Analysis on Main Controlling Factors of Tide-Dominated Estuary}

In a sedimentary system, influencing factors of sedimentary characteristics are complex, including flow rate, granularity, component of sediment, geomorphic features, climate and temperature [5]. Estuaries belong to interactive zone of river and sea. The paper mainly analyzed the influence of component of water body energy and sediment on river mouth deposit. To explore the influence, the writer set three groups of single variable comparative tests and observed sedimentary characteristics of estuary under different parameters to analyze influence of various parameters on sand sediment. From the aspect of water dynamic, the paper considered stream flow and tidal range and explored the influence of sediment combination on sand sediment at the same time.

\subsection{Influence of Stream Flow on Estuary Sediment}

Water power is the main force of sediment. Estuary sediment system happens in coastal zone where river and sea meet with each other and it is controlled by bi-directional energy. To explore the influence of stream flow on estuary sediment, five groups of models were set with different stream flows (Figure 3) with a flow rate of $100 \mathrm{~m}^{3} / \mathrm{s}, 500 \mathrm{~m}^{3} / \mathrm{s}, 1000 \mathrm{~m}^{3} / \mathrm{s}, 2000 \mathrm{~m}^{3} / \mathrm{s}$ and $5000 \mathrm{~m}^{3} / \mathrm{s}$ respectively. Through the five groups of models, we can see that when stream 
flow is lower than $1000 \mathrm{~m}^{3} / \mathrm{s}$, sediment in river mouth does not have obvious changes. And with a continuous increase of flow, sediment in river mouth starts to reduce, thus it can be seen that over large stream flow will damage the whole depositional district to a certain degree. According to the above analysis, it is believed that when tide energy of river mouth is given, the increase or decrease of stream flow will also affect sediment in estuary sand bars. A preliminary conclusion is that with the increase of stream flow, sedimentation rate of sediment will reduce, sedimentary thickness in the river mouth will decrease and tide gate will become more straight and simpler.
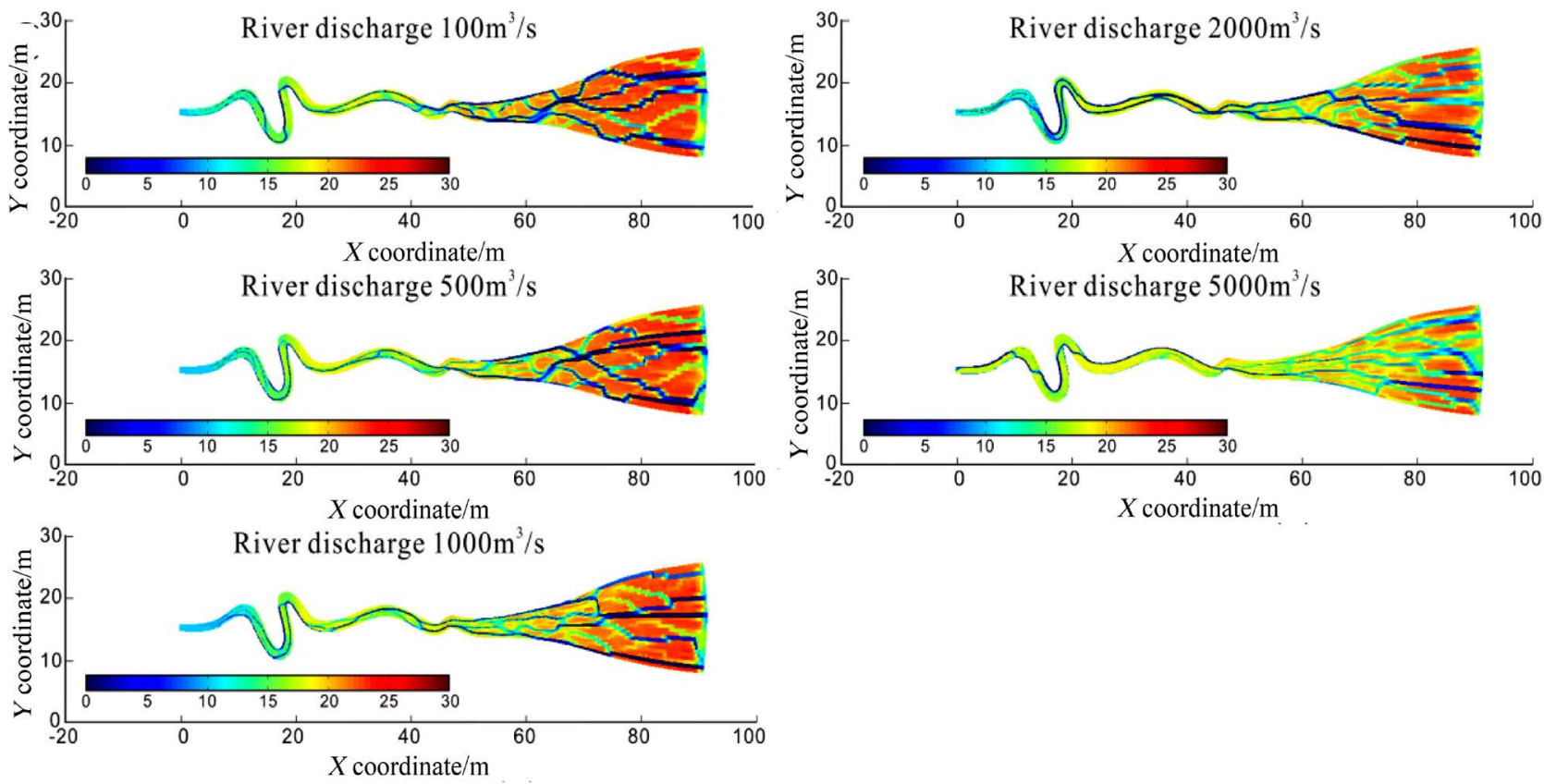

Figure 3. Comparison of numerical simulation of estuaries under different river discharge.

\subsection{Influence of Tidal Range on Estuary Sediment}

The tests set five groups of models of different tidal ranges (Figure 4) with a tidal range of $0.5 \mathrm{~m}, 1 \mathrm{~m}, 3 \mathrm{~m}, 4 \mathrm{~m}$ and $5 \mathrm{~m}$ respectively. By observing the five groups of models, we can know that the influence of tidal range has a more obvious influence on sediment at the river mouth than streams. When the tidal range is lower than $1 \mathrm{~m}$, no tide sand bar will be formed; and when the tidal range continues to increase, sediment at the river mouth will be remarkably increased. Therefore, it shows that when the river energy of estuary is given, the increase and decrease of tidal range will also have a drastic influence on sediment in estuary sand bars. A preliminary conclusion is that with the increase of the height of tide, the sedimentation rate of sediment will increase, sedimentary thickness at the river mouth will increase and the tide gate will become more complex. When the tide energy is so small that tide sand bars cannot be found in the depositional district, for stream flow, tide energy is the main agent of estuary sediment. 

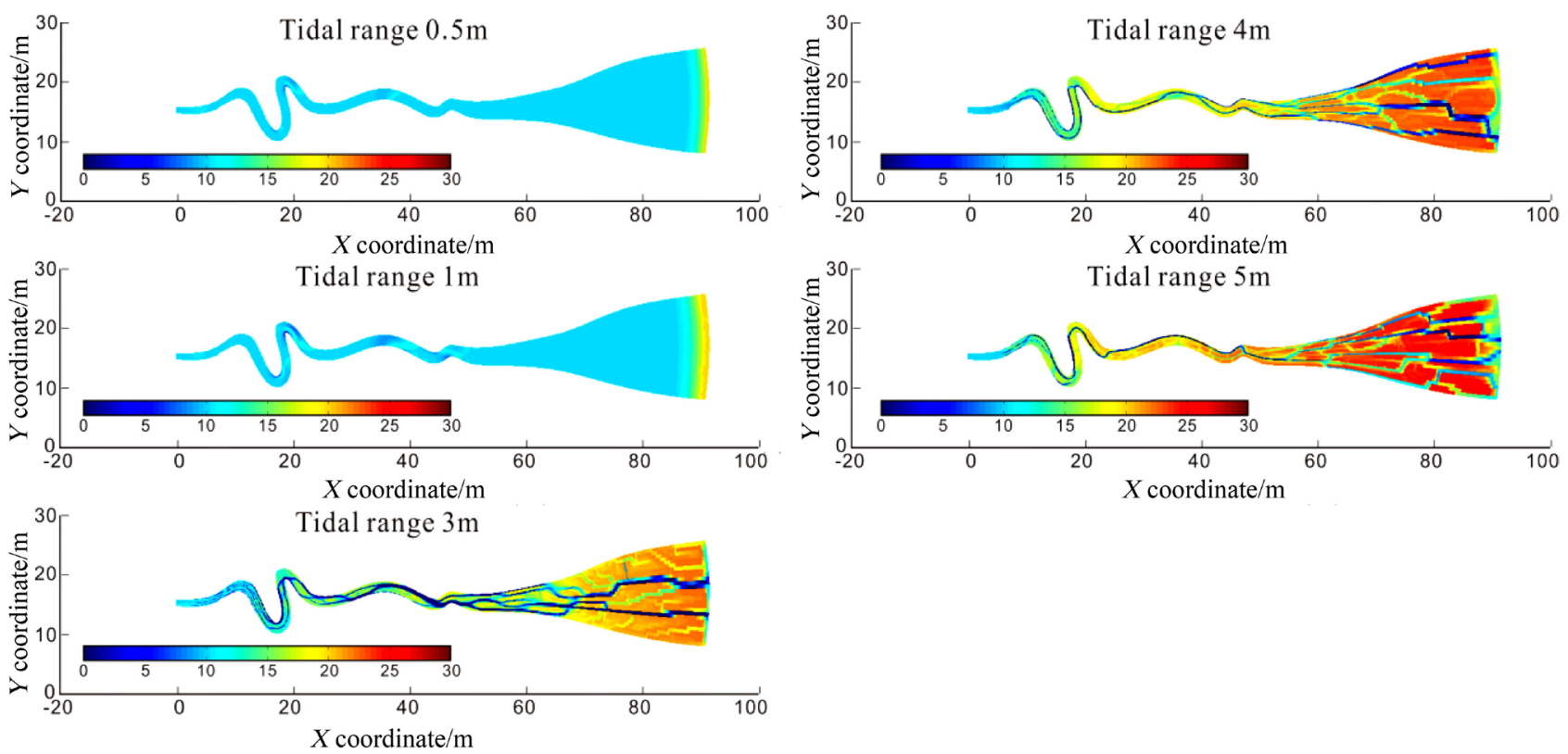

Figure 4. Comparison of numerical simulation of estuaries under different tidal differences.

\subsection{Influence of Component of Sediments on Estuary Sediment}

The physical and numerical simulation test indicates that the influence of sediment component is obvious, thus in the test, two kinds of models of different sand- and-mud ratio with different tidal ranges (Figure 5), including 5 groups, have been tested. When the tidal range is $3 \mathrm{~m}$, the sand-and-mud ratio is set to 1:1, 1:5 and 5:1 respectively. When the tidal range is $5 \mathrm{~m}$, the sand-and-mud ratio is $1: 1$ and 1:5 respectively. Through the five groups of models, it can be seen that when the sand- and-mud ratio is $1: 1$ and 1:5, sediment at the river mouth does not have obvious differences, while when the sand-and-mud ratio is
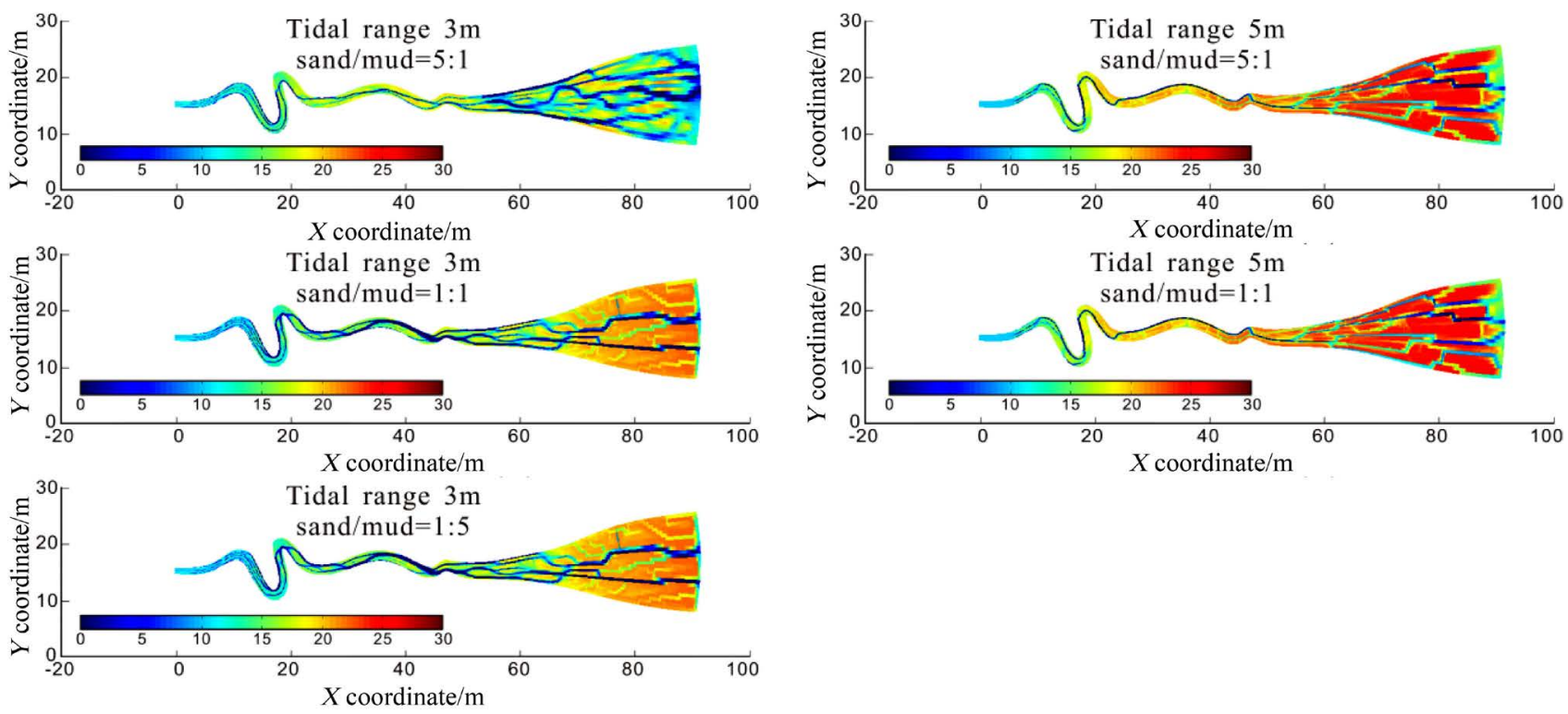

Figure 5. Comparison of numerical simulation of estuarine bay with different silt ratios. 
$5: 1$, the thickness of sediment reduces. Through analysis, it can be found that when energy at the river mouth is given, changes of component density within tide will have a certain influence on sediment in estuary sand bars, and a preliminary conclusion is that the increase and decrease of sand contents of tide have little influence on sedimentary thickness in estuary sand bar. Even when the tidal range is changed, the results will be close. When the contents of mud reduce, thickness of sand bars will reduce remarkably and tide gate will also become more complex.

Through the analysis of the three comparative tests of stream flow, tidal range and sedimentary component, it is believed that from the aspect of water power, the influence of tidal range on estuary sediment is the most obvious and the effect on steam is relatively weak. When the tidal energy is small, even if it has all the other advantages, it is difficult to form an estuarine sedimentary system because the oceans, as the main source of material, do not provide sufficient sediment. If the action of the river is too strong, the sediment is difficult to be preserved because the kinetic energy of the water body is too large, which results in the destruction of the original dam body. The formation of the estuarine bay sediment scale is smaller, and the distribution of sand body is scattered. From the aspect of sedimentary component, the increase of sand will not necessarily cause the increase of sedimentary thickness while contents of mud (viscous component) will have a great influence on sedimentary thickness.

\section{Conclusions}

1) In the process of sedimentation of estuary sand, the function of bimodal current brought by tidal action is the main reason for the formation of sand bars and also the main water power of estuary sediment. The magnitude of tidal range directly determines the sediment thickness and sedimentary morphology in estuarine estuary and is the main object of estuarine sediment analysis.

2) The influence of sedimentation brought by fluvial process on sedimentary bodies in estuary is relatively small. When the effect of fluvial process is too big, it will cause sand move towards to ocean, thus it is not suitable to save. Moreover, it will damage sedimentary bodies in estuary to a certain degree. Although the fluvial action is not so significant to estuary sediment, which is the secondary power of estuary, the river flow change will make estuary sediment change obviously.

3) In a certain quantity of energy body, component of sediment will have an obvious influence on sedimentary thickness, and mud (viscous component) in sedimentary component is the main reason for the conservation of sediment.

\section{Funding}

The project is supported by National Science Foundation of China (No. 41572081), major projects of National Science and Technology (No. 2016ZX05031-002-001). 


\section{References}

[1] Dalrymple, R.W., Mackay, D.A., Ichaso, A.A., et al. (2012) Processes, Morphodynamics, and Facies of Tide-Dominated Estuaries. Principles of Tidal Sedimentology. Springer Netherlands, 79-107.

[2] Feng, W.J., Wu, S.H., Zhang, K., et al. (2017) Depositional Process and Sedimentary Model of Meandering-River Shallow Delta: Insights from Numerical Simulation and Modern Deposition. Acta Geologica Sinica, 91, 2047-2064.

[3] Xiong, S.L. and Zeng, J. (2008) Study on Classification Index and Fluvial Processes of Tidal Estuaries. Journal of Hydraulic Engineering, 39, 1286-1295.

[4] Wang, D.D., Song, Y.K. and Guo, Y.P. (2017) A Google Earth-Based Study on Point Bar of Meandering River. China’s Manganese Industry, No. 2, 141-143.

[5] Pritchard, D.W. (1967) What Is An Estuary: Physical Viewpoint. In: Lauff, G.H., Ed., Estuaries, American Association for the Advancement of Science, Washington DC, Vol. 1, 149-176. 